\title{
Coastal environment of the past millennium recorded by a coastal dune in Fujian, China
}

\author{
JIN Jianhui ${ }^{1,2^{*}}$, LI Zhizhong ${ }^{1,2^{*}}$, JIANG Feng $^{1}$, DENG Tao ${ }^{1}$, HU Fan'gen ${ }^{1,3}$, LING Zhiyong ${ }^{4}$ \\ ${ }^{1}$ Institute of Geography, Fujian Normal University, Fuzhou 350007, China; \\ ${ }^{2}$ Fujian Provincial Key Laboratory of Subtropical Resources and Environment, Fuzhou 350007, China; \\ ${ }^{3}$ Institute of Geology and Geophysics, Chinese Academy of Sciences, Beijing 100029, China; \\ ${ }^{4}$ Qinghai Institute of Salt Lakes, Chinese Academy of Sciences, Xining 810008, China
}

\begin{abstract}
Coastal dune is a common aeolian geomorphology in a sandy coast, which records the evolution process of the aeolian landscape system and reflects the complex interaction among land surface, atmosphere and ocean. Coast is a sensitive area to global climate change. Restricted by chronology, most previous researches in China focused only on the cause of formation of coastal dunes. In recent years, the development of optically stimulated luminescence (OSL) dating provides a good method and acts as a carrier for coastal dunes to paleoclimate and paleoenvironmental studies. In this study, we selected an aeolian dune at the Anshan archaeological site, Fujian, China as the research object based on field observations. For determining their sedimentary stages and the primary influencing factors, we used the OSL dating method to construct a chronological framework for the aeolian dune. In addition, the sizes of grains were analyzed for identifying factors influencing the winter monsoon during the Medieval Warm Period (MWP) and the Little Ice Age (LIA) in this area. The results showed that the deposition of the aeolian dune was closely related to variations in the winter monsoon intensity. The changes of the winter monsoon were similar to the tendency of the East Asian winter monsoon, although there were several sub-fluctuations. From an overall perspective, the winter monsoon was strengthened during the MWP (1050-1300). The results of a power spectrum analysis showed that the intensity of the East Asian winter monsoon is correlated with sunspot activity.
\end{abstract}

Keywords: coastal dune; Optically Stimulated Luminescence; Medieval Warm Period; Little Ice Age; winter monsoon

Citation: JIN Jianhui, LI Zhizhong, JIANG Feng, DENG Tao, HU Fan'gen, LING Zhiyong. 2016. Coastal environment of the past millennium recorded by a coastal dune in Fujian, China. Journal of Arid Land, 8(5): 707-721. doi: 10.1007/s40333-016-0053-4

Extensive coastal dunes have developed in sandy coastal zones around the world as a result of the combined action of global climate change with changes in the sea level (Wu et al., 1995). Many scholars, who have conducted extensive researches on coastal dunes, have made significant advances in understanding the development of coastal dunes and aeolian processes and in reconstructing the evolution of the coastal environment (Wu and Wu, 1987; Dong, 2000; Goodwin et al., 2006; Li et al., 2011; Blumer et al., 2012). For example, Dong (2000) systematically classified the coastal dunes in the temperate zones of China. By studying the aeolian deposits on the northwestern coast of Lower Michigan, Blumer et al. (2012) found that drought and variations in hydrologic conditions are associated with the Medieval Warm Period (MWP). They also suggested the wind-sand interactions that occurred during the past 1,000 years were the result of

\footnotetext{
"Corresponding author: JIN Jianhui (E-mail: geojjh@fjnu.edu.cn); LI Zhizhong (E-mail: lizz@fjnu.edu.cn)

Received 2015-10-23; revised 2016-01-22; accepted 2016-04-01

(C) Xinjiang Institute of Ecology and Geography, Chinese Academy of Sciences, Science Press and Springer-Verlag Berlin Heidelberg 2016
} 
changes in lake level and climate. In studies on the environmental evolution of the desert areas of northern China, grain size data are commonly used as climate proxies in studies of the cyclical changes in the wind intensity (Dong et al., 1997; Li et al., 2010; Lu et al., 2010; Guo et al., 2012). Eextensive studies on changes in the Quaternary climate and physiognomy in the deserts of northern China were conducted (Yang et al., 2010). Based on regional correlation, Dong et al. (1997) explored the relationship between the feedback mechanisms behind the development of desert and sandy ground, the climatic fluctuations caused by changes in the climate and solar radiation during the most recent Ice Age, and changes in the underlying surface. Using dense optically stimulated luminescence (OSL) dating, Lu et al. (2010) suggested that the processes of sedimentation and erosion in desert sand/loess deposits were mainly controlled by climate change. Guo et al. (2012) inverted the climate change of the Badain Jaran Desert during the Holocene at a millennial timescale using grain size characteristics.

From the above findings, we can obtain abundant information which can be used for interpreting past climatic rhythms and forecasting future climate change. The climate change during the past millennium is one of the researching hotspots currently. Many studies have suggested that the MWP and the Little Ice Age (LIA) occurred during the past millennium (Hu et al., 2008; Zheng et al., 2010; Ge et al., 2013), although the climatic rhythms of the characteristic time intervals of the MWP and the LIA are different in different areas. The differences are mainly in the following: the beginnings and ends of cold and warm periods, the frequency of secondary fluctuations during a typical climatic stage, and the timing of peaks and troughs (Yu et al., 2009). In addition, small-scale and high-frequency fluctuations have a significant impact on climate change, however, the periodicity of the fluctuations is not yet clear.

The south-eastern coast of China has typical coastal dunes, some of which developed under current climate conditions, and some of which are relicts of coastal dunes and the sedimentation of ancient aeolian sand as the coast evolved. The coastal dunes that developed under modern climate conditions are the products of the combined action of wind and waves in coastal areas. The ancient sediments record the history of changes in the coastal environment. In this study, the history of sedimentary and soil processes in this area, as shown by the aeolian dune, were discussed. In particular, the sedimentary environment and wind-sand interactions during the MWP and the LIA were analyzed using OSL dating, grain size and spectra data. We used the standard deviation as a metric in the discussion to determine the grain size distribution, which is sensitive to climate change, and also used power spectra to analyze the periodicity. The results are significant for the study of the aeolian morphology of the coastal regions of south-eastern China.

\section{Study area}

Jinjiang county, Fujian province $\left(24^{\circ} 30^{\prime}-24^{\circ} 54^{\prime} \mathrm{N}, 118^{\circ} 24^{\prime}-118^{\circ} 43^{\prime} \mathrm{E}\right)$ is located on the southern lower reaches of the Jinjiang River and bordered on three sides by the sea, by higher ground in the northwest and by lower ground in the southeast. The Quanzhou Bay and the Taiwan Strait are northeast and southeast of Jinjiang, respectively. Some of the small rivers in Jinjiang flow into the Taiwan Strait. The area has rich rainfall and a humid temperate climate, whereas the oceanic climate is characterized by subtropical monsoon. The annual precipitation ranges from 911 to $1,231 \mathrm{~mm}$. The annual mean temperature ranges between $20.0^{\circ} \mathrm{C}$ and $22.0^{\circ} \mathrm{C}$, with the minimum monthly mean temperature of $11.9^{\circ} \mathrm{C}$ in January and the maximum of $28.2^{\circ} \mathrm{C}$ in July. On average, the annual sunshine hours are $2,130 \mathrm{~h}$. The prevailing wind direction during the normal year is NE or NNE. Geologically, this area lies in the middle of the shear zone that extends from Changle to Nan'ao and belongs to the metamorphic belt of the south-eastern coast of China. Granite from $\mathrm{Sxx}_{3} \mathrm{~J}_{3} \mathrm{Gz}$ (Jurassic granite) and volcanic rock from $\mathrm{Je}^{2}$ (Jurassic volcanic) are the main lithological formations, beyond them, there are Late Quaternary $\left(\mathrm{Q}_{3} 1\right.$ and $\left.\mathrm{Q}_{4} \mathrm{c}\right)$ distributions of loose sediment. The main landforms are low rolling hills and platforms, which are caused by erosion. The platforms are composed of laterite in soft hills, which are round and caused by erosion. Valleys are separated by platforms and marine deposition plains, and ridges are built by wind deposition. The zonal soil in this area is latosolic red soil (Fig. 1). 
The Anshan archaeological site $\left(24^{\circ} 36^{\prime} 30^{\prime \prime} \mathrm{N}, 118^{\circ} 39^{\prime} 20^{\prime \prime} \mathrm{E}\right)$ in Shenhu town, Jinjiang county owns shrub dune, complex dune and aeolian dune. The dunes lie on a secondary platform composed of "old red sand". In this study, we obtained the profile and samples from a shrub dune. The linear distance between the sampling site and the beach is approximately $2 \mathrm{~km}$. The elevation of the dune is $27 \mathrm{~m}$ asl, and the relative height difference is $20 \mathrm{~m}$. The dune is covered with shrubs and grasses. Yancuo Stream, which is located in the northwest of the site, runs into the Shenhu Bay from south to north.

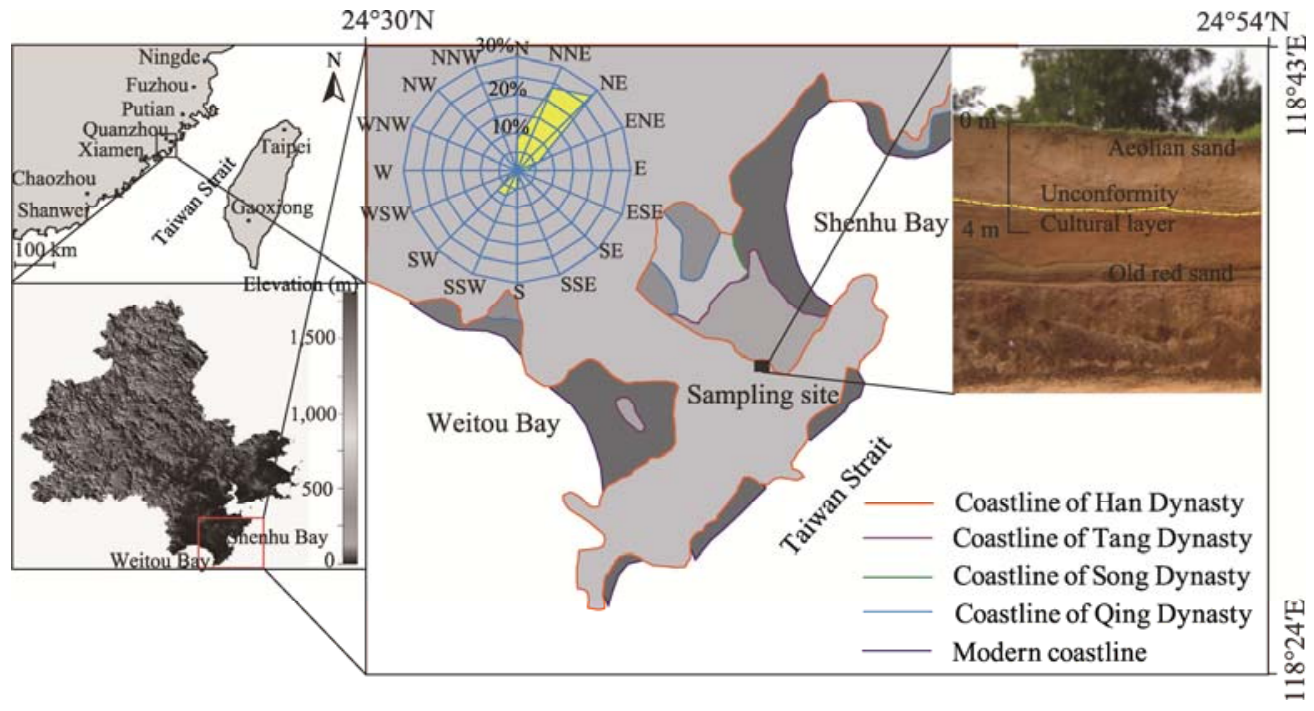

Fig. 1 The locations of the study area and sampling site

\section{Methods}

\subsection{Lithology}

We dug a 4-m long profile without reaching the bottom of the dune (Fig. 2) in 2010. As can be seen from Fig. 2, aeolian deposits in the section are obvious. And it is a section of artificially excavated and has remained on the slip face of the dune for a long time.

From the top down, the profile is divided into two parts with a total of four beds. The lower sediment is "old red sand" and the upper is dune (aeolian) sand (Fig. 2). The two are separated by a nonconformity and gently inclined surface. The surface is a post-erosional relict of an "old red sand" platform. Each stratum has a clear boundary. The section between 0 and $0.55 \mathrm{~m}$ is light grey $(5 Y 7 / 1)$ for the profile and contains light grey $(5 \mathrm{Y} 7 / 1)$ and gently inclined medium-fine sand beds. Plant roots are developed between 0 and $0.3 \mathrm{~m}$. The section between 0.55 and $3.00 \mathrm{~m}$ is a grey $(5 \mathrm{Y} 6 / 1)$ or light grey $(5 \mathrm{Y} 7 / 1)$ medium-fine sand bed. This bed exhibits gently dipping micro-bands and dozens of brown (7.5YR4/4) sand stripes. Parts of the umber sand stripes are undulating, and almost all are parallel with a small inclination angle. The maximum width of the parallel stripes is $0.5 \mathrm{~cm}$, and the minimum width is $0.2 \mathrm{~cm}$. Between 3.0 and $3.5 \mathrm{~m}$, the section of profile is yellowish-brown (10YR5/8) with developing aeolian cross-bedding at an angle of $15^{\circ}-18^{\circ}$. The section features some yellowish-red (5YR4/6) oxide stripes. Between 3.5 and $4.0 \mathrm{~m}$, there is a yellowish-red (5YR4/6) medium-dense sand bed, and the section is dark brown (7.5YR3/4) or yellowish-red (5YR4/6) with many very dark brown $(7.5 \mathrm{YR} 2.5 / 2)$ mottled iron pans between 3.5 and $3.7 \mathrm{~m}$. The section from 3.7 to $3.9 \mathrm{~m}$ is reddish-brown $(2.5 \mathrm{YR} 4 / 4)$ and dense, and it is olive brown $(2.5 \mathrm{Y} 4 / 4)$ and loose from 3.9 to $4.0 \mathrm{~m}$. A denudation surface was found at 3.5 $\mathrm{m}$ at an angle of $5^{\circ}-10^{\circ}$. According to the archaeological data (Fan et al., 2014), the profile is located close to the shore of Shenhu Bay where the primary coastal dune was formed with a direct supply of sediment from the beach face from the Han Dynasty to the early Qing Dynasty. Then, the primary dune was recomposed into a secondary sand dune by continued aeolian processes and 
separated from hydrodynamic processes of littoral zone since the middle of the Qing Dynasty; and these processes were associated with both natural factors and human activities (such as population growth, excessive deforestation and maritime embargos).

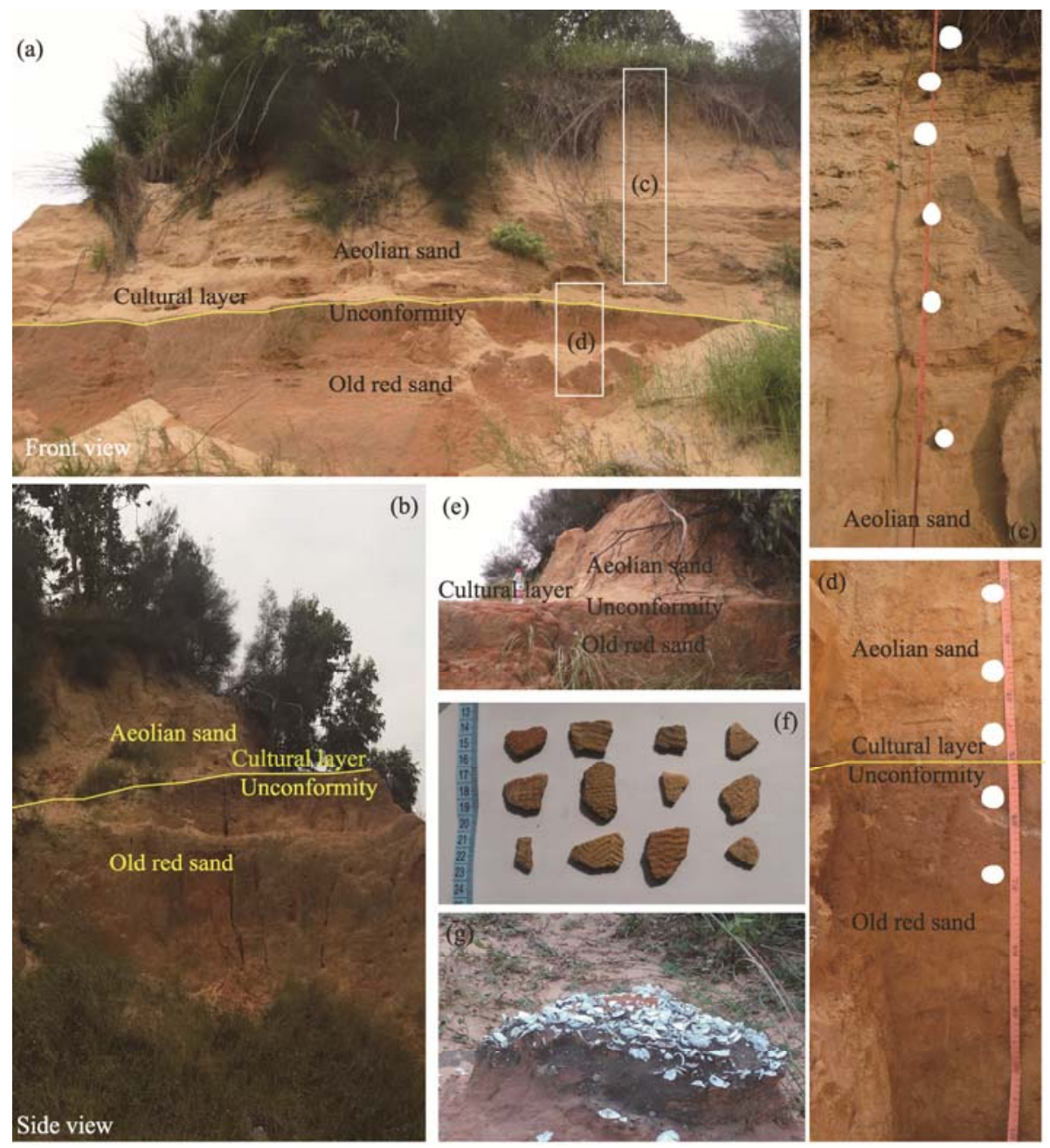

Fig. 2 Topographic features and cultural layers of the sampling profile. (a), front view of the profile; (b), side view of the profile; (c, d), the locations of the optically stimulated luminescence (OSL) samples; (e-g), cultural layers, unearthed pottery and shells, respectively.

\subsection{Experimental methods}

In this study, OSL method was employed and the signals from quartz by the single-aliquot regenerative-dose (SAR) protocol were carried out to determine the age of the dune profile in Anshan. For consistency with the data representation of previous researches, the data of OSL age in this study were converted into Western calendar (year AD) in the discussion.

\subsubsection{Equivalent dose measuring}

In total, we collected 11 samples for OSL dating. A Risø DA-20-CD thermoluminescence (TL) and OSL automatic reader produced by the Danish National Laboratory were used. This system includes a blue light-emitting diode $(\lambda=470 \pm 20 \mathrm{~nm})$ and an infrared radiation source $(\lambda=830 \mathrm{~nm})$ that can be used as excitation light sources to test the components of feldspar. The OSL signals penetrated a 7.5-mm-thick Hoya U-340 filter and then, entered a 9235QA photomultiplier; finally, the signals were tested and recorded. The artificial irradiation source is ${ }^{90} \mathrm{Sr} / \mathrm{Y}$. For obtaining an equivalent dose of natural luminescence, a blue light was chosen as the excitation source and the 
SAR protocol (Murray and Olley, 2002; Wintle and Murray, 2006) was adopted to test quartzes which are $90-125 \mu \mathrm{m}$ in sizes. The advantage of the SAR protocol is that sensitivity changes during the measurement procedure can be corrected using a signal induced by a test dose (Peng et al., 2016). Regenerative beta doses including a zero dose and a repeated dose were employed, and the corresponding sensitivity-corrected OSL signals, i.e. the regenerated OSL signals divided by the OSL signals of the subsequent test doses, were used to construct growth curves (Fig. 3). The value of De (single-aliquot De) was estimated by interpolating the sensitivity-corrected natural OSL onto a growth curve.
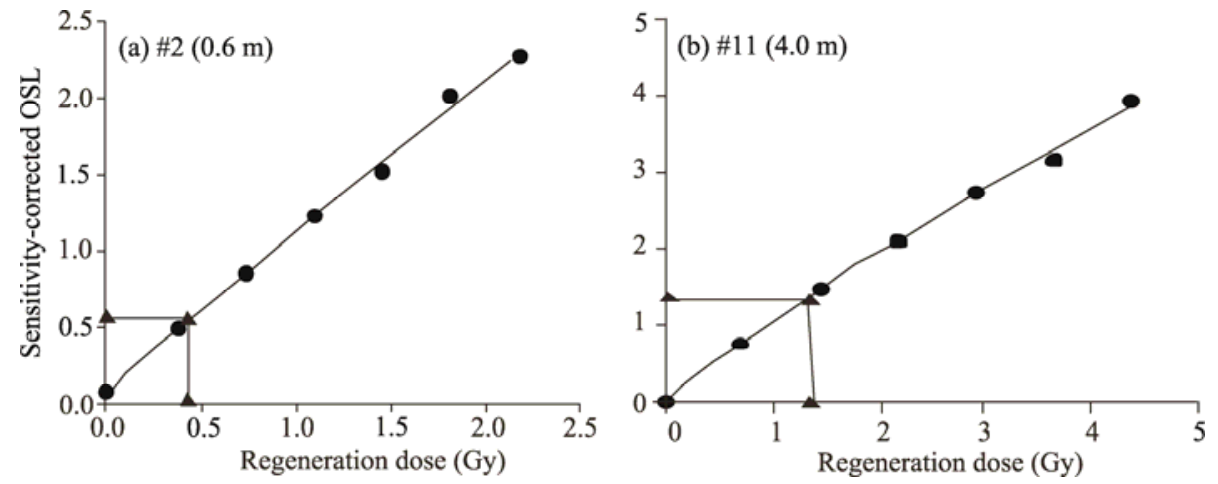

Fig. 3 The growth curves for samples 2 (a) and 11 (b) determined using the SAR (single-aliquot regenerative-dose) protocol. Triangles represents natural optically stimulated luminescence (OSL) signals and solid circles represent regenerative signals.

\subsubsection{Annual dose measuring}

To obtain the ratio of the contributions of $U$ (uranium) and Th (thorium) and the products of their decay to the environmental dose rate, we used a Daybreak583 counter to count the alpha particles. The tail of the alpha particle distribution was greater than 2,000, which was suitable for statistical analyses. An FR640 flame photometer was used to determine the $\mathrm{K}_{2} \mathrm{O}$ content in the meantime.

\subsubsection{Grain size measuring}

We sampled the sand at intervals of $2.5 \mathrm{~cm}$ from the profile and obtained 160 samples for grain size measuring. The grain size of samples were measured using a Malvern laser grain size analyser with a range of measurement of $0.02-2,000 \mu \mathrm{m}$ and a resolution of $0.01 \varphi$. We measured each sample three times to ensure that the replication error was less than $2 \%$ and used the average as the result. We analyzed four grain size parameters in this study, including the mean grain size (Mz), the standard deviation $(\sigma)$, the skewness (SK) and the kurtosis $\left(\mathrm{K}_{\mathrm{G}}\right)$ (Folk and Ward, 1957). All the grain size parameters were calculated with $\varphi$ value of grain size.

\section{Results}

\subsection{OSL data}

The OSL data of this profile are shown in Table 1. The formation process of the dune in Anshan can be divided into two stages: the first stage was 0.7 and $0.9 \mathrm{ka} \mathrm{BP}$ and the second stage was 0.1 and $0.5 \mathrm{ka} \mathrm{BP}$ (Fig. 4), which were roughly corresponding to the MWP and the LIA, respectively. However, the formation process had a visible break during the LIA. The OSL data were corresponding to the stratigraphic sequence of the section as a whole, but the results of some specific samples may be not correct. For example, some of which were older than the true ages. It was obviously related to the mineralogy properties of quartz particles ( $\mathrm{Li}$ et al., 2011). Moreover, some of which were clearly younger than the true ages. It was likely a product of weathering. The method used to estimate the annual doses can influence the reliability of the OSL ages at the same time. In this experiment, we obtained the annual dose by testing coarse quartz. And the annual dose of coarse quartz was calculated by traditional method, which was based on the radioactive element content. Therefore, the annual dose was relatively accurate. 
Table 1 Sample information and OSL (optically stimulated luminescence) ages

\begin{tabular}{ccccccc}
\hline $\begin{array}{c}\text { Sample } \\
\text { number }\end{array}$ & $\begin{array}{c}\text { Depth of } \\
\text { profile }(\mathrm{m})\end{array}$ & $\begin{array}{c}\alpha \text { particle } \\
\text { counting rate } \\
(/ \mathrm{ks})\end{array}$ & $\mathrm{K}_{2} \mathrm{O}(\%)$ & $\begin{array}{c}\text { Environmental } \\
\text { dose rate }(\mathrm{Gy} / \mathrm{ka})\end{array}$ & $\begin{array}{c}\text { Equivalent dose } \\
(\mathrm{Gy})\end{array}$ & $\begin{array}{c}\text { OSL age } \\
(\mathrm{ka} \mathrm{BP})\end{array}$ \\
\hline 1 & 0.3 & $8.85 \pm 0.20$ & 1.10 & $2.41 \pm 0.22$ & $0.246 \pm 0.043$ & $0.108 \pm 0.021$ \\
2 & 0.6 & $3.57 \pm 0.14$ & 1.86 & $2.10 \pm 0.20$ & $0.437 \pm 0.038$ & $0.208 \pm 0.028$ \\
3 & 1.0 & $3.78 \pm 0.14$ & 2.24 & $2.41 \pm 0.24$ & $0.428 \pm 0.040$ & $0.178 \pm 0.022$ \\
4 & 1.4 & $3.41 \pm 0.14$ & 1.64 & $1.90 \pm 0.18$ & $0.428 \pm 0.038$ & $0.225 \pm 0.027$ \\
5 & 1.8 & $3.34 \pm 0.14$ & 1.70 & $1.93 \pm 0.19$ & $0.455 \pm 0.053$ & $0.235 \pm 0.033$ \\
6 & 2.2 & $3.49 \pm 0.14$ & 1.52 & $1.82 \pm 0.17$ & $0.455 \pm 0.056$ & $0.250 \pm 0.037$ \\
7 & 2.6 & $6.18 \pm 0.17$ & 1.64 & $2.25 \pm 0.22$ & $0.501 \pm 0.023$ & $0.223 \pm 0.021$ \\
8 & 3.0 & $13.51 \pm 0.25$ & 2.36 & $3.82 \pm 0.39$ & $0.582 \pm 0.026$ & $0.152 \pm 0.014$ \\
9 & 3.3 & $4.98 \pm 0.17$ & 1.14 & $1.69 \pm 0.16$ & $0.801 \pm 0.087$ & $0.475 \pm 0.064$ \\
10 & 3.6 & $9.34 \pm 0.20$ & 1.22 & $2.42 \pm 0.23$ & $2.029 \pm 0.276$ & $0.839 \pm 0.132$ \\
11 & 4.0 & $6.58 \pm 0.17$ & 0.74 & $1.60 \pm 0.15$ & $1.365 \pm 0.106$ & $0.854 \pm 0.095$ \\
\hline
\end{tabular}

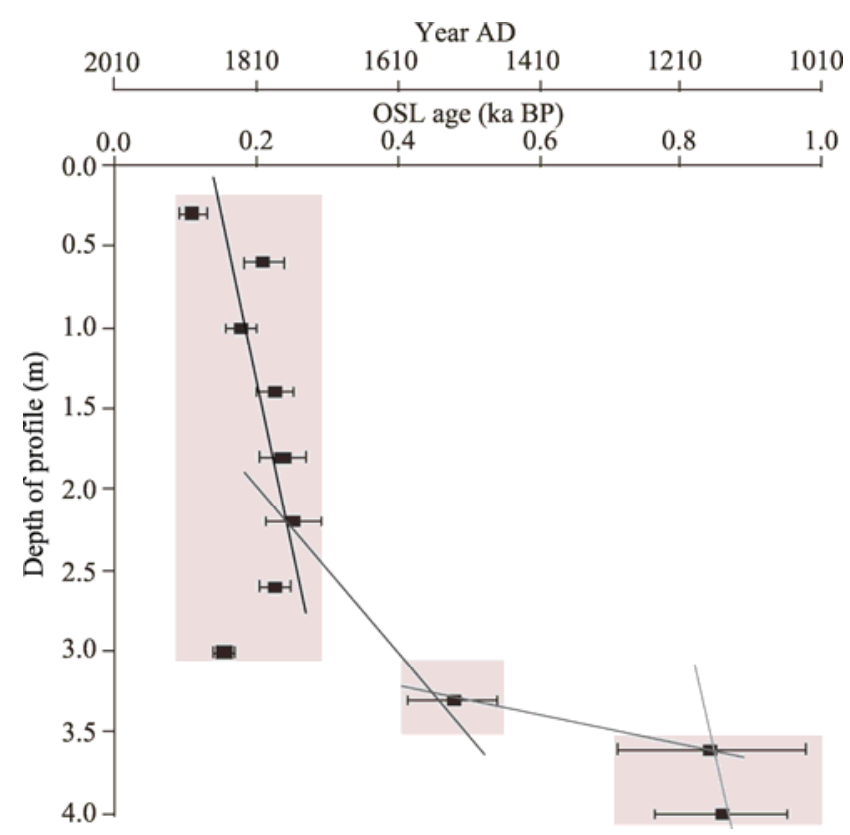

Fig. 4 Relationship between the OSL age (and its corresponding year AD) and depth of the dune profile

The modern coastal dunes in the coastal areas of southern China have developed since the middle of the Holocene, especially during the late Holocene (Wu et al., 1995). The AMS ${ }^{14} \mathrm{C}$ ages of the underlying peat horizon of coastal dunes in Xiamei, Zhangpu county, Fujian province, which is adjacent to the study area, and of shell fragments from the coastal dune in the Gulei Peninsula, which is also adjacent to the study area, were $0.70 \pm 0.05$ and $1.40 \pm 0.09 \mathrm{ka} \mathrm{BP}$, respectively. These results agreed with the dates calculated by the Fujian Provincial Museum in 2007 and 2009 (Fan et al., 2014). At depths greater than $3.5 \mathrm{~m}$, the bed ranged from light grey (5Y7/1) to grey (5Y6/1) and developed during the Ming and Qing dynasties. At depths less than $3.5 \mathrm{~m}$, the bed ranged from yellowish-brown (10YR5/8) to yellowish-red (5YR4/6) and developed during the Tang and Song dynasties. Based on our OSL ages, the maximum age of the bottom of the section was $0.854 \pm 0.095 \mathrm{ka} \mathrm{BP}$, and the minimum age was $0.108 \pm 0.021 \mathrm{ka} \mathrm{BP}$. The ages of the dune in Anshan are similar to those of other dunes in adjacent area (Li et al., 2011). Overall, the OSL ages are credible within the margin of error.

\subsection{Grain size characteristics}

Grain size is a good indicator of the sedimentary environment (Fig. 5). The samples collected at 
depths between 0 and $3 \mathrm{~m}$ were fine- or medium-grained sand that was greyish-yellow and closely graded. The grain size distribution featured a positive skewness and good classification. The sand collected at depths between 3 and $4 \mathrm{~m}$ was fine- or medium-grained sand that was yellowish-brown (10YR5/8) or yellowish-red (5YR4/6) in colour, and the grain size had a positively skewed distribution. As a whole, the classification of the lower section was not as clear as that of the upper section. According to Folk and Ward (1957), the main grain size parameters include the mean grain size (Mz; ranging from 0.86 to $2.41 \varphi$ ), the standard deviation ( $\sigma$; ranging from -2.04 to $-0.49 \varphi$ ), the skewness (SK; ranging from -0.49 to $0.18 \varphi$ ) and the kurtosis $\left(\mathrm{K}_{\mathrm{G}}\right.$; ranging from 1.87 to $5.98 \varphi$ ). These grain size characteristics were in agreement with the ones of modern coastal aeolian sands of China that were identified by Dong (2006). The frequency distributions of the samples from different beds were similar and generally single-peaked. We can, therefore, conclude that the dynamic depositional environment was relatively stable.
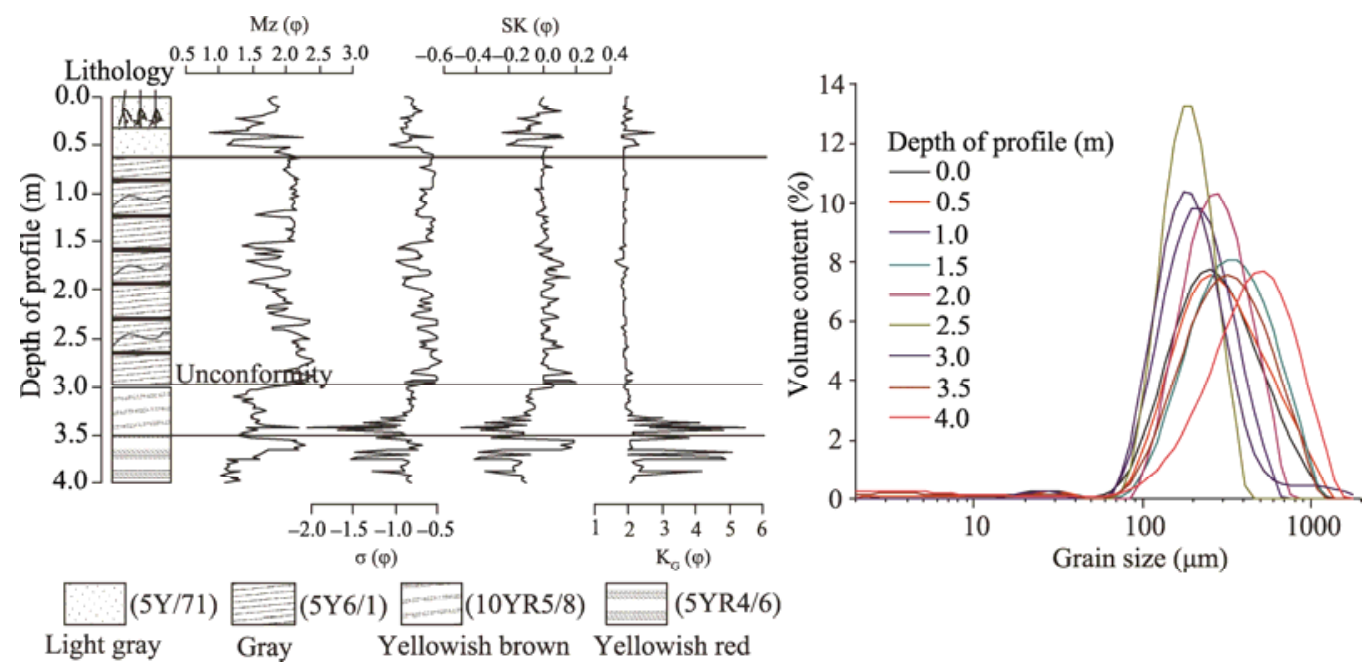

Fig. 5 Characteristics and volume content distributions of grain sizes of the sands in different depths of the dune profile. Mz, mean grain size; SK, skewness; $\sigma$, standard deviation; $\mathrm{K}_{\mathrm{G}}$, kurtosis. The wave lines in the lithologic map represent the banded and wavy brown (7.5YR4/4) sand layers.

Compared with the deposits that underwent distal and long transport in Mosuowan of Xinjiang, the dune in Anshan was proximal with short deposits that originated from the beach. The maximum and average energies required to transport sediments in Anshan were higher than the equivalent energies for Mosuowan because of the nearer provenance and shorter distance moved. From Fig. 6, we can see that the dune in Anshan showed obvious features of wind-borne deposits, and its sedimentary type was similar to that of the dunes in Mosuowan. The threshold wind velocity of sand movement is $7-8 \mathrm{~m} / \mathrm{s}$ in Mosuowan, according to the monitored field data (Ma et al., 2007). Meteorological observation data collected during the past 50 years showed that the annual average wind speed exceed $7.9 \mathrm{~m} / \mathrm{s}$ in Quanzhou (Guo et al., 2010). Because of the humid coastal climate, the beach and coastal dune sands are more humid than the inland desert sands. Therefore, the start-up wind velocity of beach and coastal sands is higher. Figure 6 also showed that the dune mobility is lower in Anshan than in Mosuowan. This could be caused by differences in several factors, including the fetch length, water content, vegetation coverage and salinity. These analytical results indicated that the dune in Anshan has the features of coastal aeolian sands.

\subsection{The sensitive grain size fraction}

The standard deviation of the grain size data reflects the diversity of the content of each grain size fraction $(\mathrm{Wu}$ and $\mathrm{Wu}, 1987)$. We extracted the sensitive grain size of each fraction using the standard deviation. The largest standard deviation was the mode of the sensitive grain size, and the peaks occurred at 174.11 and $522.30 \mu \mathrm{m}$ (Fig. 7). We only considered the environmental changes reflected by grain sizes that were greater than $65.58 \mu \mathrm{m}$ because few grains were less than 65.58 $\mu \mathrm{m}$ in sizes $(<5 \%$ of the total). The two ranges of grain size were $65.58-320.54$ and $>320.54 \mu \mathrm{m}$. 
We calculated the contents of this two grain size ranges (Fig. 8). The contentss of the two grain size ranges clearly fluctuated and, the trends of the two ranges were opposing. The contents of grain sizes between 65.58 and $320.54 \mu \mathrm{m}$ varied from $15.66 \%$ to $95.65 \%$, and the average content was $60.70 \%$. The contents of grain sizes greater than $320.54 \mu \mathrm{m}$ varied from $4.36 \%$ to $82.25 \%$, and the average was $38.17 \%$. We can conclude that the main components of the samples are composed of grain sizes that are between 65.58 and $320.54 \mu \mathrm{m}$. In addition to the height of the section, the changes in the mean grain size and the contents of grain sizes between 65.58 and $320.54 \mu \mathrm{m}$ in each fraction are also shown in Fig. 8, and both of them have similar variation tendencies. Therefore, we chose the distribution of grain sizes that are between 65.58 and 320.54 $\mu \mathrm{m}$ as the sensitive grain size composition.

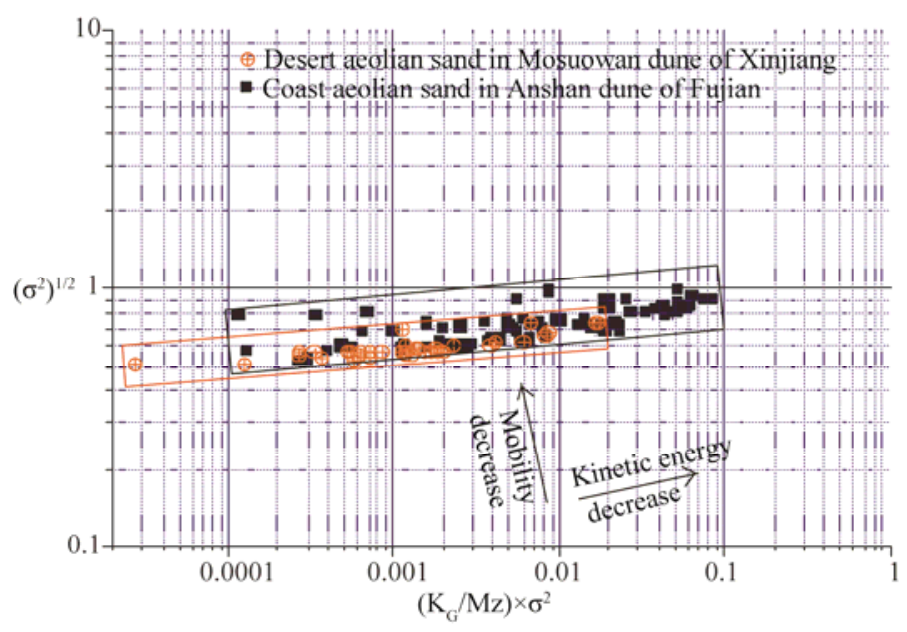

Fig. 6 A classification diagram for sedimentary origins of the sands in Anshan dune of Fujian and Mosuowan dune of Xinjiang

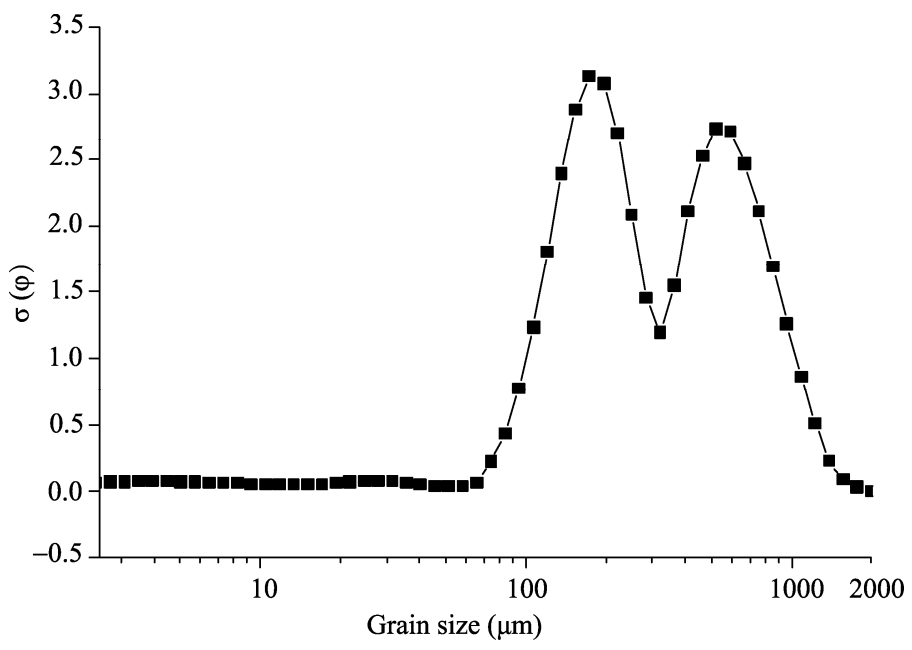

Fig. 7 Distribution of the standard deviation $(\sigma)$ of grain sizes of the sands in Anshan dune

The sensitive grain size compositions of the grain size fractions are often used to identify the variations in the Asian winter monsoon (Guan et al., 2007; Yu et al., 2014). Southern Fujian is located in the South Asian tropical monsoon region. High atmospheric pressure from Mongolia and cold waves influence it in winter, and powerful typhoons over the Western Pacific and South China Sea influence it in summer. Instrumental data show that north-easterly winds are common in autumn and winter in southern Fujian (Zeng et al., 1997). These north-easterly winds can last for 6 months or longer. Powerful uninterrupted north-easterly onshore winds provide a strong force for 
wind-blown activity and the growth of coastal dunes in southern Fujian. What's more, autumn and winter are dry seasons. The synchronicity of the dry and windy seasons is beneficial to the growth of coastal dunes. Therefore, we used the sensitive grain size composition that corresponds to grain size that are between 65.58 and $320.54 \mu \mathrm{m}$ to describe changes in the winter monsoon.
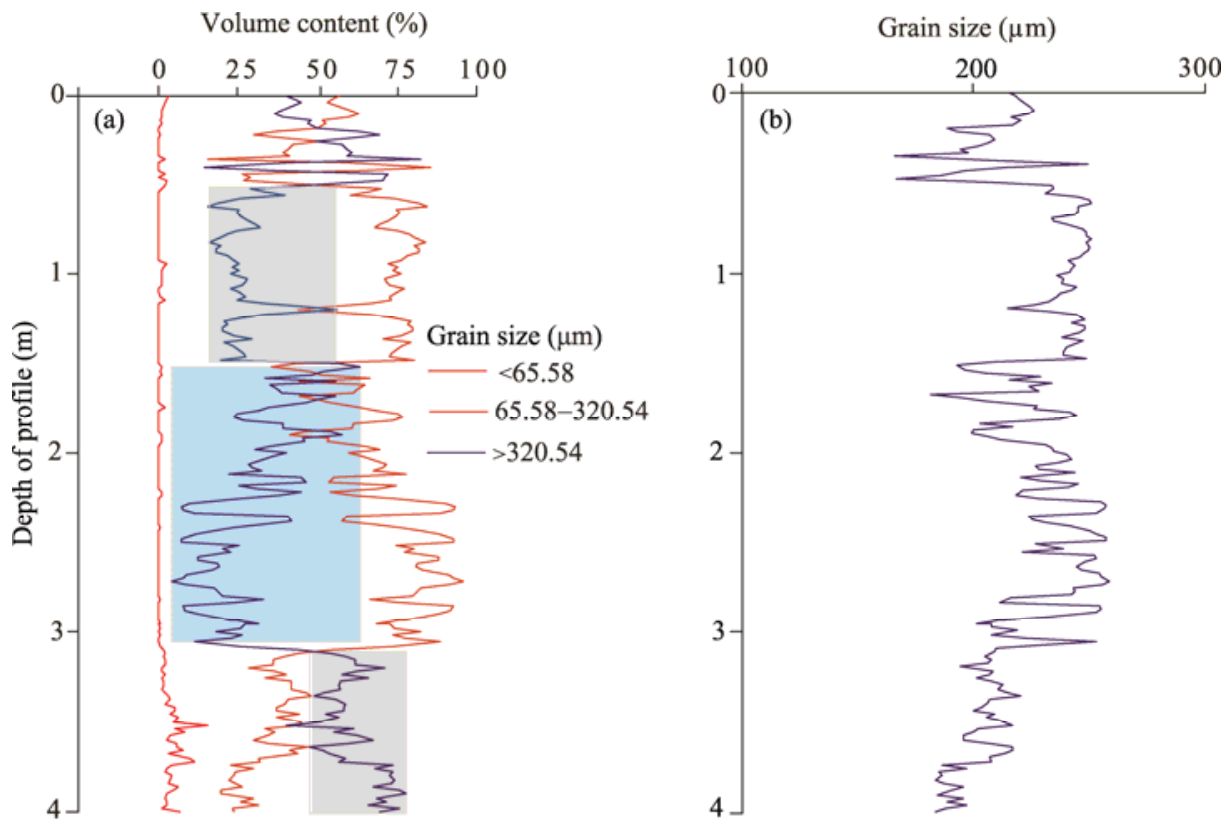

Fig. 8 Variations of the grain size fractions (a) and mean grain sizes for $65.58-320.54 \mu \mathrm{m}$ fraction (b) in different depths of the dune profile

\section{Discussion}

\subsection{Primary factors influencing the wind-sand activity}

The development of coastal dunes is influenced by many factors. Wu and $\mathrm{Wu}$ (1987) concluded that the growth of coastal dunes on the coast of southern China is primarily affected by the source of the sands, onshore winds and topography. The development of coastal dunes is also closely related to geotectonic movement, sea-level fluctuations, typhoons and storm surges. Of course, reactivation of the sandy aeolian dunes is also related to the settlement and land use in this area (Zeng, 1997). According to the ancient books such as the "Illustrated Handbook of the Fujian Coast", the coastal regions of Fujian province, which were originally fertile fields, have been covered by wind-shaped dunes since 1810 (Jin et al., 2015).

However, there is no significant correlation between development of coastal dunes and storm surges or sea-level fluctuations in our study area (Hu et al., 2013). Based on the changes in sea level recorded by the late Quaternary coastal aeolian dunes on the south-eastern coast of Fujian, we know that coastal aeolian dunes can be deposited during periods of low and high sea levels (Hu et al., 2012). The development of this section during the MWP and the LIA directly shows that there is no significant relationship between the development of coastal dune in Anshan and sea-level fluctuations. Studies of the frequency of typhoons landing in Fujian province indicate that there is no close relationship between dune development and typhoons.

Because of the interaction between the topographic trough and the "narrow pipe effect", the study area is one of the largest offshore fetches in winter. North-easterly winds prevail in winter and south-westerly winds prevail in summer. The north-easterly winds in winter are more frequent than the south-westerly winds in summer. The winter monsoon lasts from September to May next year and prevails from October to March next year. The winter monsoon is characterized by a high average wind speed, more gale days and long heydays. In summer, the dynamics and stability of 
the south-westerly winds are poor (Fig. 1). The force of the north-easterly winds is controlled by the East Asian winter monsoon. Based on a comparison of the developmental periods of dunes on the western coast of Japan (Tamura et al., 2011) and the eastern Yilan coast of Taiwan, China (Dörschner et al., 2012) and the dune in Anshan, we found that the dune in Anshan developed when the winter monsoon was strong. Temperature and humidity variations can strengthen or weaken factors that influence the development of dunes. A warm and dry climate promotes the evaporation of water from beach sands, so a reduction in the amount of water favours the development of coastal dunes. Moreover, a declining rainfall trend benefits the development of wind-drift sand in the coastal region. Therefore, the coastal dunes on the west coast of the Taiwan Strait are mainly influenced by the force of the winter monsoon. Their development processes reflect the strength of local winds and partly reflect variations in the temperature and humidity. A powerful winter monsoon favours the development of coastal dunes, whereas a weak winter monsoon weakens it.

\subsection{Climatic change processes}

\subsubsection{Dune deposits during the Medieval Climate Anomaly (MCA)}

The MWP is also known as the MCA. The MWP is a dominant climatic characteristic or trend. Geologic records of the MWP, or the MCA, have been found on every continent. Although there is no agreement about the beginning and end dates of the MWP, most studies suggest a range from 900 to 1400 (Wang, 2011). During the MWP, the dune in Anshan developed between 1050 and 1300, including the late North Song Dynasty (1050-1127), the Southern Song Dynasty (1127-1260), and the early Ming Dynasty (1260-1300).

As shown in Fig. 9, the East Asian winter monsoon became strong and the forcing appeared to have increased between 1050 and 1300, as indicated by the sensitive average grain size. The trend corresponds approximately to the curve for the East Asian winter monsoon (Yancheva et al., 2007; Zhou et al., 2007). The temperature anomaly in eastern China increased after decreasing during this period. There was also a cold phase of the MWP during the early South Song Dynasty (Ge, 2011). Zhou and Zhao (2009) suggested that the Aleutian low, the Asian land high and the East Asian winter monsoon became stronger in winter during periods of global warming. The strengthening East Asian winter monsoon removed heat and water effectively and, therefore, influenced the area's temperature and humidity. Zhou et al. (2011) also concluded that the land-sea thermal difference was large and precipitation was high in northern China and low in southern China during the MWP. These climate records show that the winter monsoon was powerful during this period and validate the relationship between the winter monsoon and the area's temperature and humidity which was suggested by Zhou and Zhao (2009).

Influenced by the East Asian winter monsoon circulation, droughts occurred frequently in eastern China during the period from 1035 to 1230 (Man, 2009). In drought-prone years, the meridionality of the atmospheric circulation in the Asian middle and upper latitudes was strong, and cold surge events occurred frequently, which favoured the winter monsoon and southward outbreaks of cold waves (Sun and Sun, 1995). Historical documents stated that the snow line in China was located south of Lingnan in the first half of the $12^{\text {th }}$ century, and the modern snow line has moved one degree north (Man, 2009). In the late $12^{\text {th }}$ century, the temperature was generally low on the south-eastern coast of China. There are several records of rivers and lakes freezing (Man, 2009). In 1178, litchi trees in Fujian died in winter because of low temperatures and more frequent cold waves. This also occurred in 1110 in Fujian. In 1190, the summer was still cool, and several inches of snow fell in Jianning in December (Ge, 2011). These historical documents confirm that the East Asian winter monsoon became stronger during the MWP. Some natural climate records also confirm the occurrence of this cooling event, which was caused by the East Asian winter monsoon. These records are corresponding to the development process of the dune in Anshan recorded by the OSL data from 1100 to 1200 .

The winter monsoon strengthened despite some bumps during the MWP in the sedimentary environment of the study area. A cold phase and an environment (with low temperature, drought, and cold surge events on the southeast coast) that strengthened the winter monsoon favoured the 
deposition of sand. It is reasonable to assume that the dune in Anshan was mainly deposited during the cold event of the $12^{\text {th }}$ century, which was corresponding to the early Southern Song Dynasty (1127-1200).

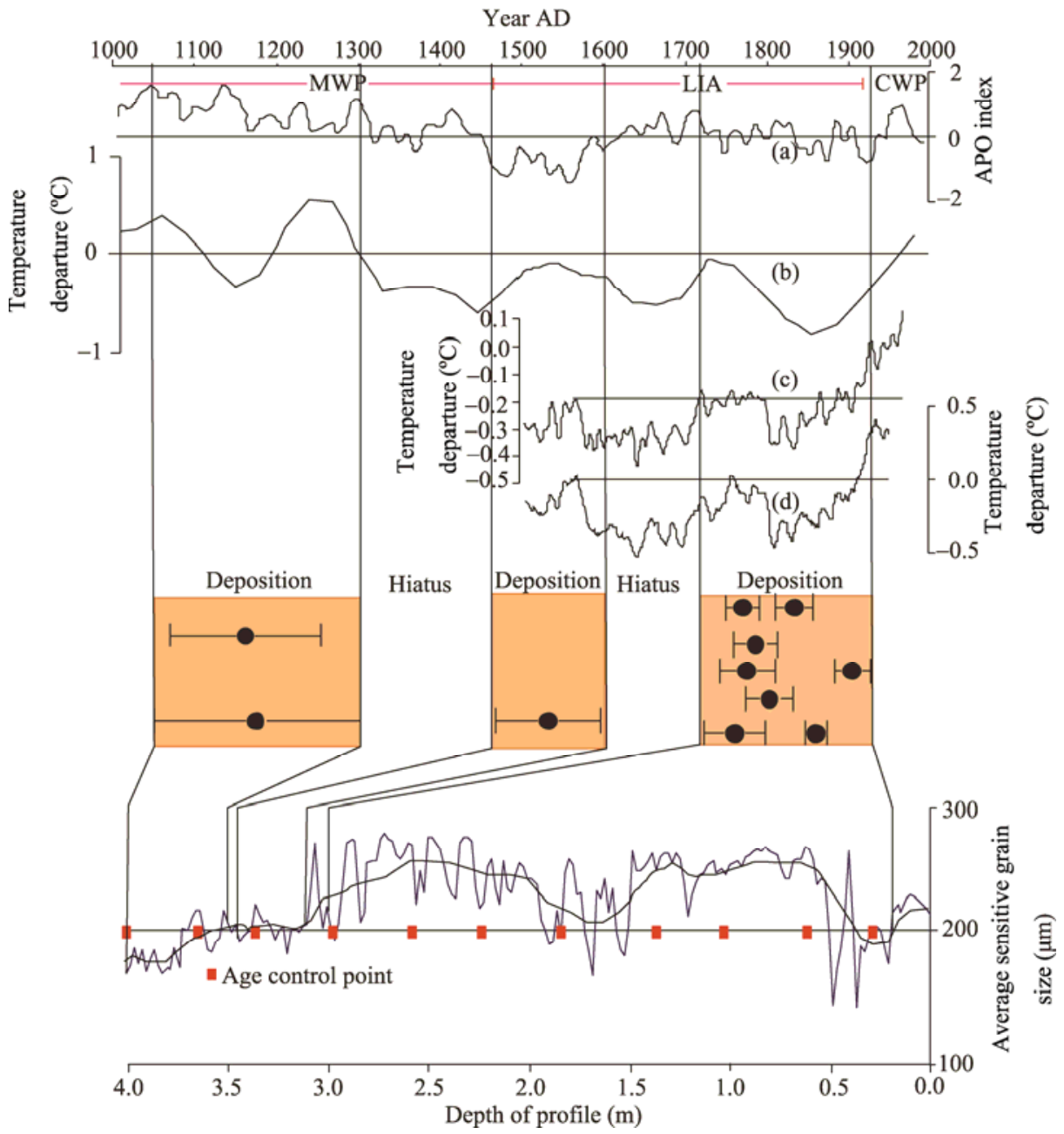

Fig. 9 The change in the climate substitute index compared with the developmental stages of the dune in Anshan. (a), the Asian-Pacific Oscillation (APO) index (Zhou et al., 2011); (b), the temperature departure of the winter half-year in eastern China (Zheng et al., 2000); (c, d), the temperature departure of the northern hemisphere analyzed by Mann and Jones (2003) and Hegerl et al. (2006), respectively. MWP, Medieval Warm Period; LIA, Little Ice Age; CWP, Current Warm Period.

\subsubsection{Sedimentary environments and changes in the winter monsoon during the LIA}

The LIA is the last sudden climate change that has occurred since the onset of the Holocene. There were two sedimentary periods (1470-1600 and 1720-1900) during this period in the study area. The winter monsoon was strong throughout the LIA, but there was an obvious climatic optimum during 1720 and 1900 (Fig. 9), which recorded short intervals of events.

Based on temperature changes that occurred in China over the past thousand years, the LIA included several cold periods, each of which lasted for between 100 and 200 years. The temperature was relatively cold during the $15^{\text {th }}, 17^{\text {th }}$ and $19^{\text {th }}$ centuries (Ge et al., 2013). The three cold periods correspond approximately to the developmental periods of the dune. We only obtained dates from 1470 to 1600 because of the small deposit thickness. This period corresponded to cold stages $\mathrm{I}$ and $\mathrm{II}_{1}$ in the division by Wang (2011). Some studies have suggested that cold stage I was short and not very cold (Wang et al., 1998), and occurred later on the southeast coast than it did in northern, central and eastern China. After 1480, the climate became 
colder and the winter monsoon became stronger in southern China, indicating that the LIA had begun (Ge, 2011). From 1527 to 1605 , the snow line moved one degree south in southern China (Zhang and Huang, 2000). There are numerous records of frost-related injuries because of the cold weather in Fujian. For instance, in winter of 1501, ice was up to half an inch thick, and litchi trees froze and withered in Putian, Fujian. And the fruit harvest was small in spring of 1532. In spring of 1609, the climate suddenly became cold, and snow fell in Changle, Fujian. These records show that the strength of the winter monsoon from 1470 to 1600 coincided with the average sensitive grain size determined from the data (approximately $200 \mu \mathrm{m}$ ) in this study.

There was a distinct cold climate in northern China, northwestern China, the Tibetan Plateau and the lower regions of the Yangtze River from 1610 to 1720 (Wang et al., 1998) that corresponded to cold stages $\mathrm{II}$ and $\mathrm{II}_{2}$. However, during this period there was no deposition in our study area, which showed that the cold climate was not typical of south-eastern Fujian. However, monsoons with frequent fluctuations had strengthened or weakened during this period (Yang et al., 2013). According to historical documents, the winter monsoon strengthened in some specific years at the start of the $17^{\text {th }}$ century. For example, the land was bare because of drought in summer and autumn around Zhangzhou and Quanzhou in Fujian from 1626 to 1627. In 1628, drought affected southern Fujian again.

The period from 1720 to 1900 corresponds approximately with cold stage III of the LIA. In this period, the sediment in the section was extremely thick. In this study, eight samples were obtained for OSL dating: five were from the $18^{\text {th }}$ century and three were from the $19^{\text {th }}$ century. The winter monsoon was much stronger in the $18^{\text {th }}$ century than in the $19^{\text {th }}$ century in the coastal area around south-eastern Fujian. The average sensitive grain size was approximately $250 \mu \mathrm{m}$ in the $19^{\text {th }}$ century. As indicated by the average sensitive grain size, the winter monsoon intensity in this period was much greater than that in cold stage I. From Fig. 9, it can be seen that the sand drift events that occurred in approximately 1770 were weak and this period was a relatively warm phase of cold stage III of the LIA.

\subsection{A possible mechanisms of climate change and spectral evidence}

Solar radiation is the direct driving force for the East Asian monsoon on a centennial timescale (Wang et al., 2005). By comparing the sequence of variations in the average sensitive grain size of coastal dune in Anshan and the total solar irradiance determined by Steinhilber et al. (2009), we found, based on the sequence, that the East Asian winter monsoon responded to cycles of solar activity on a centennial timescale. Several solar minima were recorded in the dune profile in Anshan (Fig. 10). The average sensitive grain size was high when the solar activity declined, and the high average indicated that the winter monsoon strengthened. We can therefore conclude that climate events on a centennial timescale directly correspond to solar activity (Wang et al., 2005). The Maunder Minimum of 1640-1720 was an obvious minimum (Wang et al., 2012) during which the sensitive grain size was high.

To further investigate the effect of solar forcing on the East Asian monsoon on a relatively short timescale, we analyzed the time series of the average sensitive grain size using the power spectral density (PSD) analysis method defined in REDFIT 37 (Fig. 10). Our analysis showed that with 95\% confidence, there were 59-, 42-, 27-, 17-, 15-, 13-, 11- and 10-year cycles, and there was also a 125 -year cycle with $90 \%$ confidence. During the past 1,000 years, there have been quasi-periodic oscillations of 200,90,140,60, 22 and 11 years in the solar activity; and 11 years was the main period (Yin et al., 2007). The 60- or 59-year cycles corresponded to the sunspot cycles. The maximum sunspot cycle length was 15 years, the minimum length was 8.2 years and the average length was 11.02 years. The spectrum of the sensitive grain size showed the cycles of $15,13,11$, and 10 years. There was a relationship between sunspot bursts and the strength of the East Asian winter monsoon in the study area. There was also a 10-13-year cycle in the Asian-Pacific thermal difference (Zhao et al., 2011). Therefore, we can also determine the nature of the close relationship between the Asian-Pacific thermal difference and sunspot activity. In addition, fluctuations in the winter monsoon are also influenced by volcanic activity and greenhouse gas intensity (Xiao et al., 2012). There was a good correspondence between the sequence of volcanic activity (Mann et al., 
2005) and developmental phases of the dune in Anshan. There were 32 years of volcanic eruptions during the period from 1500 to 1920 , and the intensity of the volcanic activity increased as the winter monsoon became stronger (Zhang and Huang, 2000). El Nino is an important factor in climate change on a centennial timescale in the South Pacific and on a decadal scale in the subtropics (Mann et al., 2005). The winter temperature series for 1470-1988 in southern China showed that the chance of a year having a cold winter was $76 \%$ in El Nino years or the years that preceded them (Huang et al., 1990).

The above analysis showed that solar radiation is the primary factor that affects the Asian monsoon system on a centennial timescale. The Asian monsoon system is impacted by factors such as volcanic activity and the El Nino Southern Oscillation (ENSO). In different areas, in the context of large circulations led by the ENSO, the intensity and differences in the response of solar radiation are not clear. The mechanism by which solar activity impacts climate by affecting the atmospheric circulation remains controversial (Mann et al., 2005; Yancheva et al., 2007). This study reveals that there is a close relationship between solar activity and the local East Asian monsoon. This research is important in the study of the mechanisms of climate change.

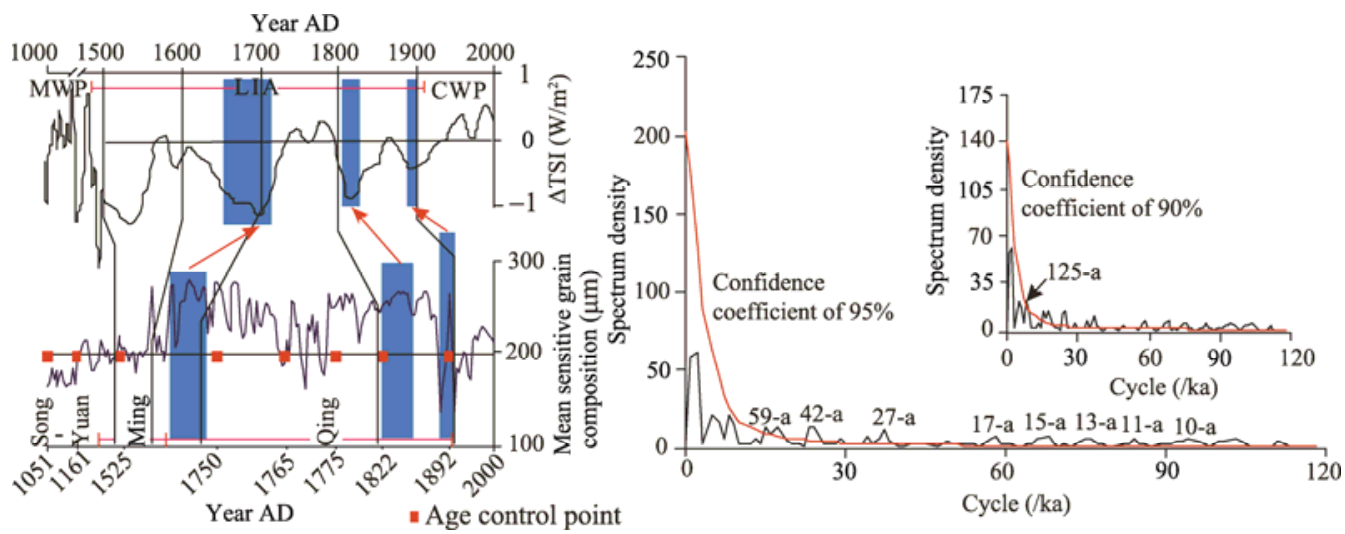

Fig. 10 Results of the sensitive grain group and the solar radiation compared with those of a power spectrum density analysis. TSI, total solar irradiance. The orange lines in the right figures represent different confidence coefficients.

\section{Conclusions}

We established the sequence of sand changes in Anshan over the past approximately 1,000 years using OSL dating and grain size data. We also discussed the variations in the characteristics and the drivers of the winter monsoon during the MWP and the LIA. Our preliminary conclusions are as follows:

(1) The strength of winter monsoon is one of the crucial factors that have important influences on sand deposition and the reactivation of sandy aeolian dunes in Anshan. In the last thousand years, there have been at least three phases of wind-sand interactions. The dune developed during both the MWP (1050-1300) and the LIA (1470-1600 and 1720-1900).

(2) The changes in the winter monsoon in the study region are in agreement with the changes in the East Asian winter monsoon. The winter monsoon strengthened during the MWP (1050-1300), and there was a short period when the winter monsoon weakened between 1720 and 1900 .

(3) A clear relationship between the intensity of the East Asian winter monsoon and sunspot activity is shown in the power spectra. More research on the mechanism by which solar activity influences climate via the general atmospheric circulation is needed.

\section{Acknowledgements}

This work was financially supported by the National Natural Science Foundation of China (41301012, 41271031, U1405231) and the Natural Science Foundation of Fujian Province (2013J01153). 


\section{References}

Blumer B E, Arbogast A F, Forman S L. 2012. The OSL chronology of aeolian sand deposition in a perched dune field along the northwestern shore of Lower Michigan. Quaternary Research, 77(3): 445-455.

Dong G R, Chen H Z, Wang G Y, et al. 1997. The evolution of deserts with climatic changes in China since 150 ka B.P. Science in China Series D: Earth Sciences, 40(4): 370-382.

Dong Y X. 2000. Classification of coastal dunes in temperate zone in China. Journal of Desert Research, 20(2): 159-165. (in Chinese)

Dong Y X. 2006. The coastal aeolian geomorphic types and their distribution pattern in China. Marine Geology \& Quaternary Geology, 26(4): 99-104. (in Chinese)

Dörschner N, Reimann T, Wenske D, et al. 2012. Reconstruction of the Holocene coastal development at Fulong Beach in north-eastern Taiwan using optically stimulated luminescence (OSL) dating. Quaternary International, 263: 3-13.

Fan X C, Cheng L, Liu G J, et al. 2014. The Anshan sand dunes archaeological sites of Bronze Age in Jinjiang, Fujian. Cultural Relic, (2): 4-16. (in Chinese)

Folk R L, Ward W C. 1957. Brazos river bar: a study in the significance of grain size parameters. Journal of Sedimentary Petrology, 27(1): 3-26.

Ge Q S. 2011. Climate Change of Different Dynasties in China. Beijing: Science Press, 436-440. (in Chinese)

Ge Q S. Zheng J Y, Hao Z X, et al. 2013. General characteristics of climate changes during the past 2000 years in China. Science China Earth Sciences, 56(2): 321-329.

Goodwin I D, Stables M A, Olley J M. 2006. Wave climate, sand budget and shoreline alignment evolution of the Iluka-Woody Bay sand barrier, northern New South Wales, Australia, since 3000 yr BP. Marine Geology, 226(1-2): 127-144.

Guan Q Y, Pan B T, Gao H S, et al. 2007. Instability characteristics of the East Asian Monsoon recorded by high-resolution loess sections from the last interglacial (MIS5). Science in China Series D: Earth Sciences, 50(7): 1067-1075.

Guo T T, Gao W Y, Gao Y, et al. 2010. An analysis of the climate characteristics for Taiwan Strait. Marine Forecasts, 27(1): 53-58. (in Chinese)

Guo Y H, Li B S, Wen X H, et al. 2012. Holocene climate variations on millennium-scale from grain-size record of CGS1 segment in the Badain Jaran Desert, China. Journal of Desert Research, 32(5): 1248-1255. (in Chinese)

Hegerl G C, Crowley T J, Hyde W T, et al. 2006. Climate sensitivity constrained by temperature reconstructions over the past seven centuries. Nature, 440(7087): 1029-1032.

Hu C Y, Henderson G M, Huang J H, et al. 2008. Quantification of Holocene Asian monsoon rainfall from spatially separated cave records. Earth and Planetary Science Letters, 266(3-4): 221-232.

Hu F G, Li Z Z, Jin J H, et al. 2012. A primary research on multiphase development pattern of "old red sand" in Jingjiang coast of south east Fujian. Quaternary Sciences, 32(6): 1207-1220. (in Chinese)

Hu F G, Li Z Z, Jin J H, et al. 2013. Coastal environment evolution record from Anshan coastal aeolian sand of Jinjiang, Fujian Province, based on the OSL dating. Acta Geographica Sinica, 68(3): 343-356. (in Chinese)

Huang Z M, Liang J Y, Liu Z J. 1990. Characteristics of variation in South China climate for the past 500 years. Journal of Tropical Meteorology, 6(4): 332-339. (in Chinese)

Jin J H, Li Z Z, Hu F G, et al. 2015. Mid-Holocene coastal environment and human activities recorded by a coastal dune in Fujian Province, China. Acta Geographica Sinica, 70(5): 751-765. (in Chinese)

Li Z W, Li B S, Wang F N. 2011. A review on the research status of forming mechanism of coastal dunes. Journal of Desert Research, 31(2): 357-366. (in Chinese)

Li Z Z, Ling Z Y, Chen X L, et al. 2010. Late Holocene climate changes revealed by grain-size cycles in Takemukul Desert in Yili of Xinjiang. Scientia Geographica Sinica, 30(4): 613-619. (in Chinese)

Lu H Y, Li L P, Yi S W, et al. 2010. A perspective on deposition and erosion of the sand-loess system in North China. Earth Science Frontiers, 17(5): 336-344. (in Chinese)

Ma S H, Ge F, Chen X G, et al. 2007. The spatial-temporal distribution of maximum instantaneous wind speed and the control of active dunes in Gurbantunggut Desert. Resources Science, 29(4): 46-53. (in Chinese)

Man Z M. 2009. Climate Change Research in Chinese History. Jinan: Shandong Education Press, 229-239. (in Chinese)

Mann M E, Jones P D. 2003. Global surface temperatures over the past two millennia. Geophysical Research Letters, 30(15): 1820.

Mann M E, Cane M A, Zebiak S E, et al. 2005. Volcanic and solar forcing of the tropical Pacific over the past 1000 years. Journal of Climate, 18(3): 447-456.

Murray A S, Olley J M. 2002. Precision and accuracy in the optically stimulated luminescence dating of sedimentary quartz: a status review. Geochronometria, 21: 1-16.

Peng J, Dong Z B, Han F Q. 2016. Optically stimulated luminescence dating of sandy deposits from Gulang county at the 
southern margin of the Tengger Desert, China. Journal of Arid Land, 8(1): 1-12.

Steinhilber F, Beer J, Fröhlich C. 2009. Total solar irradiance during the Holocene. Geophysical Research Letters, 36(19): L19704, doi: 10.1029/2009GL040142.

Sun S Q, Sun B M. 1995. The relationship between the anomalous winter monsoon circulation over East Asia and summer drought/flooding in the Yangtze and Huaihe river valley. Acta Meteorologica Sinica, 53(4): 440-450. (in Chinese)

Tamura T, Bateman M D, Kodama Y, et al. 2011. Building of shore-oblique transverse dune ridges revealed by ground-penetrating radar and optical dating over the last 500 years on Tottori coast, Japan Sea. Geomorphology, 132(3-4): 153-166.

Wang S W, Ye J L, Gong D Y. 1998. Climate in China during the Little Ice Age. Quaternary Sciences, (1): 54-64. (in Chinese)

Wang S W. 2011. The Holocene Climate Changes. Beijing: China Meteorological Press, 126-176. (in Chinese)

Wang S W, Wen X Y, Huang J B. 2012. Will a new grand minimum of solar activity come soon? Progressus Inquisitiones de Mutatione Climatis, 8(2): 154-156. (in Chinese)

Wang Y J, Cheng H, Edwards R L, et al. 2005. The Holocene Asian monsoon: links to solar changes and North Atlantic climate. Science, 308(5723): 854-857.

Wintle A G, Murray A S. 2006. A review of quartz optically stimulated luminescence characteristics and their relevance in single-aliquot re-generation dating protocols. Radiation Measurements, 41(4): 369-391.

Wu Z, Wu K G. 1987. Sedimentary structure and developing model of coastal dunes along the northeastern coast of Hainan Island, China. Acta Geographica Sinica, 42(2): 129-141. (in Chinese)

Wu Z, Huang S, Hu S Z. 1995. Aeolian Geomorphology Research in South China. Beijing: Science Press, 29-53. (in Chinese)

Xiao D, Zhou X J, Zhao P. 2012. Numerical simulation study of temperature change over East China in the past millennium. Science China Earth Sciences, 55(9): 1504-1517.

Yancheva G, Nowaczyk N R, Mingram J, et al. 2007. Influence of the intertropical convergence zone on the East Asian monsoon. Nature, 445(7123): 74-77.

Yang X L, Chen F H, Yuan D X, et al. 2013. Climate change during Little Ice Age with high-resolution stalagmite record in the three-gorges reservoir area. Scientia Geographica Sinica, 33(5): 629-634. (in Chinese)

Yang X P, Scuderi L, Paillou P, et al. 2010. Quaternary environmental changes in the drylands of China-a critical review. Quaternary Science Reviews, 30(23-24): 3219-3233.

Yin Z Q, Ma L H, Han Y B, et al. 2007. Long-term variations of solar activity. Chinese Science Bulletin, 52(20): $2737-2741$.

Yu M T, Lin Z S, Du J L, et al. 2009. Multi-Scale analysis of the Last Millennium climate variations in greenland derived from ice core oxygen isotope. Journal of Glaciology and Geocryology, 31(6): 1037-1042. (in Chinese)

Yu M T, Zhang H Y, Gong Z Q, et al. 2014. The monsoon components in Qingfeng old red sands and their formation epoch, Pingtan Island, Fujian Province. Scientia Geographica Sinica, 34(3): 352-357. (in Chinese)

Zeng C S, Chen J C, Wu Y G. 1997. A summary of “old red sand” research in coastal southeast China. Journal of Oceanography in Taiwan Strait, 16(3): 363-370. (in Chinese)

Zhang W Q, Huang Z G. 2000. The Little Ice Age and its environmental effects in the tropical zone of China. Acta Geographica Sinica, 55(6): 744-750. (in Chinese)

Zhao P, Zhou X J, Liu K. 2011. Decadal-centennial-scale change in Asian-Pacific summer thermal contrast and solar activity. Chinese Science Bulletin, 56(28-29): 3012-3018.

Zheng J Y, Shao X M, Hao Z X, et al. 2010. An overview of research on climate change in China during the past 2000 years. Geographical Research, 29(9): 1561-1570. (in Chinese)

Zhou B T, Zhao P. 2009. Inverse correlation between ancient winter and summer monsoons in East Asia? Chinese Science Bulletin, 54(20): 3760-3767.

Zhou H Y, Guan H Z, Chi B Q. 2007. Record of winter monsoon strength. Nature, 450(7168): E10-E11.

Zhou X J, Zhao P, Liu G, et al. 2011. Characteristics of decadal-centennial-scale changes in East Asian summer monsoon circulation and precipitation during the Medieval Warm Period and Little Ice Age and in the present day. Chinese Science Bulletin, 56(28): 3003-3011. 